\title{
Complementary alternative medicine use among postpartum mothers in a primary care setting: a cross-sectional study in Malaysia
}

Nik Farah Nik Yusof Fuad', Siew Mooi Ching ${ }^{2,3^{*}}$ (D), Dayangku Hayaty Awg Dzulkarnain², Ai Theng Cheong ${ }^{2}$ and Zainul Amiruddin Zakaria ${ }^{4}$

\begin{abstract}
Background: Complementary alternative medicine (CAM) is widely used among postpartum mothers to maintain their well-being. This study aims to determine the prevalence and factors associated with CAM use among postpartum mothers in a primary-care clinic in Malaysia.

Methods: This is a cross-sectional study of 725 postpartum mothers, aged 18 and above, attending a primary-care clinic. The systematic sampling method was used to recruit patients through a structured, self-administered questionnaire. Data analysis was conducted using SPSS version 23. Multiple logistic regression was used to identify the predictors of CAM use among postpartum mothers.

Results: The prevalence of CAM use among postpartum mothers was $85.5 \%$. Manipulative body therapies, including massage, reflexology, hot stone compression and body wrapping were the most widely used methods of CAM (84.1\%) among postpartum mothers, followed by biological-based therapies (33.1\%). More than half of the respondents (52.1\%) opted to use CAM, as they had observed good results from other CAM users. However, our study showed that $57.1 \%$ of mothers who consumed herbal medicine reported neonatal jaundice in their newborn. The median of the expenditure on CAM usage was 250 Malaysian Ringgits, or USD 61.3 per month. According to multiple logistic regression analyses, being Muslim ( $O R=5.258,95 \% \mathrm{Cl}: 2.952-9.368)$, being Malay $(\mathrm{OR}=4.414,95 \%$ Cl: 1.18-16.56), having a higher educational level $(\mathrm{OR}=2.561,95 \% \mathrm{Cl}: 1.587-4.133)$ and having delivered via spontaneous vaginal delivery (OR: 5.660, 95\% Cl: 3.454-9.276) had a significantly positive association with CAM use among postpartum mothers.

(Continued on next page)
\end{abstract}

\footnotetext{
* Correspondence: sm ching@upm.edu.my

${ }^{2}$ Department of Family Medicine, Faculty of Medicine and Health Sciences, Universiti Putra Malaysia, 43400 Serdang, Malaysia

${ }^{3}$ Malaysian Research Institute on Ageing, Universiti Putra Malaysia, Serdang 43400, Malaysia

Full list of author information is available at the end of the article
}

(C) The Author(s). 2020 Open Access This article is licensed under a Creative Commons Attribution 4.0 International License, which permits use, sharing, adaptation, distribution and reproduction in any medium or format, as long as you give appropriate credit to the original author(s) and the source, provide a link to the Creative Commons licence, and indicate if changes were made. The images or other third party material in this article are included in the article's Creative Commons. licence, unless indicated otherwise in a credit line to the material. If material is not included in the article's Creative Commons licence and your intended use is not permitted by statutory regulation or exceeds the permitted use, you will need to obtain permission directly from the copyright holder. To view a copy of this licence, visit http://creativecommons.org/licenses/by/4.0/ The Creative Commons Public Domain Dedication waiver (http://creativecommons.org/publicdomain/zero/1.0/) applies to the data made available in this article, unless otherwise stated in a credit line to the data. 


\begin{abstract}
(Continued from previous page)
Conclusions: The prevalence of CAM use was high (8 out of 10) among postpartum mothers. Postpartum mothers who are Malay, Muslim, have a higher educational level and who have had spontaneous vaginal delivery tended to use CAM more. Manipulative body therapies, including massage, reflexology, hot stone compression and body wrapping, were the most widely used forms of CAM, followed by biological-based therapies. More than half of the mothers who consumed herbal medicine reported neonatal jaundice in their newborn. Thus, education to increase awareness regarding the consumption of herbs is urgently required in this country.
\end{abstract}

Keywords: Complementary alternative medicine, Postpartum mothers, Primary care, Malaysia, Prevalence

\section{Background}

Complementary and alternative medicine (CAM) is defined as a group of diverse medical and healthcare systems that are not conventionally practised or fully integrated into a country's dominant healthcare system [1]. CAM is commonly classified, according to National Center for Complementary and Alternative Medicine (NCCAM), into the following categories: alternative medical systems, biologically-based therapies, manipulative body therapies, mind-body therapies and energyhealing therapies [2]. In Malaysia, CAM is classified into six groups, including traditional Malay medicine (Malay herbs, cupping and massage), traditional Chinese medicine (acupuncture \& moxibustion, Chinese herbs, Chinese cupping and Qi Gong), traditional Indian medicine (Ayurveda, Siddha, Unani, yoga and naturopathy), homeopathy, Islamic medical practices and complementary therapies (mind-body medicine, biological-based therapy, manipulative therapy and energy medicine) [3].

A few studies have found that CAM is frequently used for patients with chronic diseases, such as hypertension and diabetes $[4,5]$, as well as acute illnesses like dengue and herpes simplex [6-8]. They are also commonly used by postpartum mothers to reduce pain and postpartum blood loss by promoting wound healing and improving uterine recovery, along with increasing the production of breast milk. Further, studies have shown that, by using CAM, postpartum mothers' general well-being can be enhanced by reducing weight, relieving constipation and improving symptoms of insomnia [9-14]. Some of them also believe that naturopathy using abdominal hot stone application or massage post-delivery can improve uterine involution and abdominal muscle tone [15]. There are controversial or contradictory findings about the most common types of CAM used during post-partum period. In the states of United, the mind-body practices, followed by manipulative body therapies and biologicalbased therapies [11] were the commonest practice among postpartum women $[10,11]$ On the other hand, in Malaysia, naturopathy with abdominal message and herbs usage are the commonest practice in local studies $[15,16]$. Studies have also shown that relaxation therapy, aromatherapy and massages have increased in popularity among postpartum women to alleviate their health problems, including general malaise, stress and postpartum depression [17].

\section{Methods \\ Setting}

This is a cross-sectional study of patients registered with a primary healthcare clinic in Keramat, Kuala Lumpur, Malaysia. It covers a total population of 66,605 people [18]. The study was conducted over a three-month period from January 2018 to March 2018.

\section{Inclusion criteria}

The inclusion criteria for the study were women aged 18 years and above, who had their latest delivery within 12 months of the study period. The exclusion criteria included those who were intellectually challenged or clinically unstable during the study period. The sample size was calculated using the Lemeshow formula [19] based on the prevalence rates of CAM usage of 24.2 and $35.4 \%$, according to different age groups in a previous study by Birdee GS et al. in the United States [10]. Sample size is calculated with the power of study $80 \%$ and significance level, $\alpha$ at 0.05 with $95 \%$ confidence interval, using two sample proportion formula as below:

$$
\begin{aligned}
\mathrm{n}= & \frac{\left[\mathrm{Z}_{1-\mathrm{a} 2}(\sqrt{ } 2 \mathrm{P}(1-\mathrm{P}))+\mathrm{Z}_{1-\beta}(\sqrt{\mathrm{P} 1}(1-\mathrm{P} 1)+\mathrm{P} 0(1-\mathrm{P} 0))\right]^{2}}{(\mathrm{P} 1-\mathrm{P} 0)^{2}} \times \\
& 2 \mathrm{Z} 1-\alpha / 2=1.96 \text { for } \alpha=0.05 ; \mathrm{z} 1-\beta=0.84 \text { for } 80 \% \text { power of studyP1 }= \\
& \text { Estimated proportion of one population of the outcomeP0 }= \\
& \text { Estimated proportion of second population of the outcomeP }=\frac{(\mathrm{P} 1+\mathrm{P} 0)}{2}
\end{aligned}
$$

The significant and important factors obtained from the previous research (3) are calculated. The largest sample size is yielded from the age (years) factor. Therefore, the formula is calculated as below: Age 18 $-30=\mathrm{P} 1$, Age $30-49=\mathrm{P} 0, \quad \mathrm{P} 1=0.242, \quad \mathrm{P} 0=0.354, \quad \mathrm{P}=(0.242+0.354) /$ $2=0.298$.

$$
\begin{aligned}
& \mathrm{n}=\frac{[1.96(\sqrt{ } 2(0.298)(1-0.298))+0.84(\sqrt{ } 0.242(1-0.242)+0.354(0.646))]^{2}}{(0.242-0.354)^{2}} \times 2 \\
& =522
\end{aligned}
$$

Account for $80 \%$ of respondent rate $=522 / 0.8=652.5$; Account for $90 \%$ eligibility rate $=652.5 / 0.9=725$. The 
final sample size calculated is 725 , which takes into account a non-respondent rate of $20 \%$, non-eligibility rate of $10,80 \%$ power and a significance level of 0.05 .

\section{Data collection}

A face-to-face interview was conducted using an adapted, structured questionnaire. After obtaining ethical approval, we approached each participant and explained the nature of the study before obtaining written consent of their participation. A systematic sampling method was used to recruit respondents in this study. The estimated number of postpartum women who came for postnatal follow-up was 30 patients per day, or 1800 patients in 3 months. Since the estimated sample size was 725 , a sampling interval of two was used - as a constant - during recruitment for the study. A starting number of 1 was selected randomly from the Maternal Child Health registration counter.

\section{Data collection instrument}

The adapted questionnaire was structured based on the Maternal Health Record Book published by the Ministry of Health, Malaysia (MOH) [20]. The questionnaire was initially prepared in English by the author. The contents were reviewed by an expert panel comprising three family physicians. Forward and backward translations were performed by two certified translators into Malay and English. The questionnaire was a self-administered type of questionnaire, divided into two sections. The first section included patients' sociodemographic and obstetrical information. The second section explored the experience, types, durations, the reasons for CAM use and the satisfaction level with CAM use. A pilot study involving 73 patients, $10 \%$ of the actual sample size, was conducted to pretest the questionnaire and estimate the likely response rate. Recruitment was done via the systematic-sampling method, with every one in two patients registered at the maternal and child-health clinic for postnatal clinical follow up at the same clinic. Findings from this pilot study were not included in the data analysis of the actual study.

\section{Operational definition}

A postpartum mother is an individual in the period between having given birth to a child up to 1 year after delivery [21]. CAM use, in this study, is defined as the use of any of the following therapies: biological-based therapies, manipulative body therapy, mind-body therapy, whole medical systems - including acupuncture, Ayurveda and homeopathy, energy medicine, etc. [3].

\section{Data analysis}

Statistical Package for Social Sciences (SPSS) version 23.0 was used to analyze the data collected in the study.
Descriptive analysis was used to describe the characteristics of the respondents in terms of frequencies, percentages, means, and standard deviations. In this study, the chi-square test was used for categorical data and the independent $\mathrm{t}$-test (or Mann-Whitney $\mathrm{U}$ test) for the continuous data to identify the relationships between the usage of CAM among postpartum mothers and sociodemographic and obstetrical factors. Multivariate logistic regression was used to identify the predictors of CAM usage. All variables with the $p$-value $<0.25$ in the univariate analysis, as well as the clinically significant variables, were entered into the multiple logistic regression. The dependent variable was CAM use among postpartum mothers. The independent variables were age, ethnicity, religion, education level, employment status, household income, parity, delivery method and maternal complications.

\section{Ethical approval}

Ethical approval was obtained from the Medical Research and Ethics Committee (MREC), Ministry of Health Malaysia (NMRR-16-2474-32,261) and MREC JKEUPM, Universiti Putra Malaysia (UPM/TNCPI/ $\mathrm{RMC} / 1.4 .18 .2)$ prior to data collection.

\section{Results}

\section{Socio-demographic characteristics}

A total of 735 postpartum women were recruited for this study, with a response rate of $98.6 \%$. No missing data were noted in our study. Table 1 shows the sociodemographic and obstetrical information of the study respondents. The mean age of the study respondents was $31.2 \pm 4.8$, with a range of $18-34$. The respondents were predominantly Malay Muslims (94.5\%), with more than half of them having attained tertiary educational level (66.1\%). Only $5.8 \%$ of the respondents reported complications following delivery.

\section{Prevalence of CAM use}

The prevalence of CAM use among postpartum mothers was $85.5 \%(n=620 / 725)$. Most respondents used CAM for between 30 to 44 days, with a median of 30 days. The median monthly expenditure on CAM was 250 Malaysian Ringgits (USD $=60.35$ ). Table 2 shows the different types of CAM utilized by postpartum mothers who attended the clinic. The most common type of CAM used was manipulative body therapy ( $84.1 \%)$, followed by biological-based therapy (33.1\%). In our study, we found that neonatal jaundice was also found in $57.1 \%$ of newborns whose mothers consumed herbal medicine.

\section{Reasons for CAM use and source of information}

As shown in Table 3, more than half of the respondents opted to use CAM as they had observed positive results 
Table 1 Sociodemographic and Obstetric data of study respondents in Klinik Keramat, Malaysia $(n=725)$

\begin{tabular}{|c|c|c|}
\hline Variable & Frequency N (\%) & Mean \pm SD/ \\
\hline- & - & Median (IQR) \\
\hline Age, years & & $31.2 \pm 4.8$ \\
\hline \multicolumn{3}{|l|}{ Race } \\
\hline Malay & $673(92.8)$ & \\
\hline Chinese & $26(3.6)$ & \\
\hline Indian & $10(1.4)$ & \\
\hline Others & $16(2.2)$ & \\
\hline \multicolumn{3}{|l|}{ Religion } \\
\hline Muslim & $685(94.5)$ & \\
\hline Buddhism & $16(2.2)$ & \\
\hline Hindu & $7(1.0)$ & \\
\hline Others & $17(2.3)$ & \\
\hline \multicolumn{3}{|l|}{ Education Level } \\
\hline No formal education & $1(0.1)$ & \\
\hline Primary school & $14(1.9)$ & \\
\hline Secondary school & 231 (31.9) & \\
\hline College/University & $479(66.1)$ & \\
\hline \multicolumn{3}{|l|}{ Employment status } \\
\hline Unemployed & $266(36.7)$ & \\
\hline Employed & $459(63.3)$ & \\
\hline Household Income per month (RM) & & $4000(3000)$ \\
\hline \multicolumn{3}{|l|}{ Parity } \\
\hline Primiparous & $276(38.1)$ & \\
\hline Multiparous & 449 (61.9) & \\
\hline \multicolumn{3}{|l|}{ Delivery method } \\
\hline Spontaneous vaginal delivery & $489(67.4)$ & \\
\hline Assisted vaginal delivery & $21(2.9)$ & \\
\hline Caesarian section delivery & $215(29.7)$ & \\
\hline \multicolumn{3}{|l|}{ Complication after Delivery } \\
\hline No & $683(94.2)$ & \\
\hline Yes & $42(5.8)$ & \\
\hline Deep vein thrombosis & $2(0.3)$ & \\
\hline Bleeding & $13(1.8)$ & \\
\hline Perineal infection & $1(0.1)$ & \\
\hline Depression & $3(0.4)$ & \\
\hline Others $^{a}$ & $23(3.2)$ & \\
\hline \multicolumn{3}{|l|}{ Duration of CAM use (days) } \\
\hline $1-29$ & $200(32.3)$ & $30(38)$ \\
\hline $30-44$ & $236(38.1)$ & \\
\hline$>45$ & $184(29.7)$ & - \\
\hline
\end{tabular}

${ }^{a}$ Wound breakdown, retained placenta, haemorrhoids, neck pain, late onset pregnancy induced hypertension, anemia \& breast engorgement
Table 2 Types of CAM used by postpartum mothers in Klinik Keramat, Malaysia $(n=725)$

\begin{tabular}{lll}
\hline Types of CAM & Frequency $(\mathrm{N})$ & Percentage (\%) \\
\hline Manipulative body therapy & 610 & 84.1 \\
Massage & 555 & 76.6 \\
Hot stone compression & 488 & 67.3 \\
Body wrapping & 447 & 61.7 \\
Reflexology & 6 & 0.8 \\
Biological-based therapies & 240 & 33.1 \\
Herbal Medicine & 240 & 33.1 \\
Mind body therapy & 3 & 0.4 \\
Yoga & 2 & 0.3 \\
Qi Gong & 1 & 0.1 \\
Whole medical system & 12 & 1.7 \\
Homeopathy & 10 & 1.4 \\
Acupuncture & 1 & 0.1 \\
Ayurveda & 1 & 0.1 \\
Energy Medicine & 0 & 0 \\
Sauna and cupping & 6 & 0.8 \\
\hline
\end{tabular}

from other CAM users (52.1\%). However, a quarter of them (27.5\%) stated that they simply wanted to 'try it out'. Most postpartum mothers who had used CAM reported improved overall physical health $(61.8 \%)$ with a reduction in stress after delivery (15.2\%), and an increased amount of breast milk (13.7\%). Most users stated that they were satisfied with the CAM they had been using (80.3\%).

\section{Sources of information on CAM use}

A majority of the users reported receiving information on CAM from their family members $(85 \%)$, followed by friends (7.3\%) and media (5.8\%).

\section{Factors associated with CAM use}

Table 4 shows the association between CAM use among postpartum mothers and socio-demographic factors and obstetrical factors. Unadjusted univariate logistic regression shows that ethnicity, religion, educational level and delivery method have a significant relationship with CAM use in postpartum mothers. Subsequently, multivariate logistic regression was used to analyze all the independent variables with $p$-values lower than 0.25 in the univariate logistic regression to determine the predictors of CAM use in postpartum mothers.

Table 5 shows that Malay postpartum mothers are 4.414 times (95\% confidence interval [CI]: 1.176-16.562, $p=0.028)$ more likely to use CAM than non-Malays. Further, Muslims are also at 5.01 times more likely to use CAM than non-Muslims (95\% CI: 1.136-22.082, $p=$ 0.033). Postpartum mothers who attained a tertiary 
Table 3 Reasons of CAM use and source of information among postpartum mother in Klinik Keramat, Malaysia $(n=725)$

\begin{tabular}{|c|c|c|}
\hline Variables & Frequency $(\mathrm{N})$ & Percentage (\%) \\
\hline \multicolumn{3}{|l|}{ Reasons for CAM use } \\
\hline Good example from other users of CAM & 323 & 52.1 \\
\hline Just to try out & 171 & 27.6 \\
\hline Routine practice and family tradition & 73 & 11.8 \\
\hline To treat other diseases (co-morbidity) & 27 & 4.4 \\
\hline Believe modern medicines are harmful & 22 & 3.5 \\
\hline Not satisfied with conventional medicine & 4 & 0.6 \\
\hline \multicolumn{3}{|l|}{ How CAM has helped } \\
\hline Improved overall physical health & 383 & 61.8 \\
\hline Reduced stress after delivery & 94 & 15.2 \\
\hline Increased breast milk & 85 & 13.7 \\
\hline Lose weight & 43 & 6.9 \\
\hline Others $^{\mathrm{a}}$ & 15 & 2.4 \\
\hline \multicolumn{3}{|l|}{ Satisfaction level } \\
\hline Very unsatisfied & 0 & 0 \\
\hline Unsatisfied & 4 & 0.6 \\
\hline Neutral & 71 & 11.5 \\
\hline Satisfied & 498 & 80.3 \\
\hline Very satisfied & 47 & 7.6 \\
\hline \multicolumn{3}{|l|}{ Source of Information } \\
\hline Family & 527 & 85 \\
\hline Friends & 45 & 7.3 \\
\hline Media & 36 & 5.8 \\
\hline Doctor & 7 & 1.1 \\
\hline Others $^{b}$ & 5 & 0.8 \\
\hline
\end{tabular}

${ }^{a}$ reduced body ache, achieved body relaxation, attained body heat, speed up wound healing and bleeding cessation \& no effect at all

a Neighbours, know by themselves \& village midwife

educational level are also 2.561 times more likely to use CAM than those who only have an education background of secondary level and below (95\% CI: 1.587$4.133, p<0.001)$. Finally, mothers who delivered via vaginal delivery had a higher likelihood of using CAM in comparison to those who delivered through caesarean section (odds ratio [OR]: 5.660, 95\% CI: 3.454-9.276).

\section{Discussion}

The prevalence of CAM usage among postpartum mothers in the study population was high (85.5\%), which is consistent with previous local studies and other Asian countries, which have shown prevalence values between 45 and $95.4 \%[9,13-16,22,23]$. The prevalence of CAM use reported in a tertiary hospital in Malaysia was 87.3 and $83.2 \%$ in a district health clinic in Malaysia $[15,16]$. A possible reason for the high consumption of CAM among postpartum mothers in Asia could be their belief that CAM can help mothers recover strength, relax, minimize the risk of infection, restore their body-heat imbalance and facilitate uterine recovery [24]. Furthermore, most CAM users think that CAM is safe to use, along with being easily available and cheap $[15,25,26]$. Our study also shows that the median expenditure on CAM per month by the postpartum mothers was only RM250 (USD = \$60.35). Further, the median duration of CAM use among participants was approximately 30 days (IQR: 38). This corresponds to the duration of the confinement period in most Asian countries, which is approximately $30-40$ days [24].

The most common CAM modality used in this study is manipulative body therapy, which includes massages, reflexology, hot stone compression and body wrapping. The finding is similar with another two local studies [15, 16]. Next is biological-based therapy, which comprises mainly herbal medicine and whole medical systems including acupuncture, Ayurveda and homeopathy. Our findings are consistent with a study in China, where Chinese mothers in the postpartum period predominantly utilized manipulative therapy, most often opting 
Table 4 Comparison in categorical variables between postpartum mothers in KK Keramat with or without CAM use in Malaysia $(n=$ 725)

\begin{tabular}{|c|c|c|c|}
\hline Variables & CAM users, $n=620(\%)$ & Non-CAM users, $n=105(\%)$ & $p$-value \\
\hline$\overline{\text { Age }}$ & $31.1 \pm 4.7$ & $32.0 \pm 4.9$ & 0.064 \\
\hline Monthly household income & $4000(3200)$ & $4000(2950)$ & 0.138 \\
\hline Ethnicity & & & $<0.001$ \\
\hline Non-Malay & $22(42.3)$ & $30(57.7)$ & \\
\hline Malay & $598(88.9)$ & $75(11.1)$ & \\
\hline \multicolumn{4}{|l|}{ Religion } \\
\hline Non-Muslim & $15(37.5)$ & $25(62.5)$ & $<0.001$ \\
\hline Muslim & $605(88.3)$ & $80(11.7)$ & \\
\hline Education Level & & & $<0.001$ \\
\hline Secondary level and below & $194(78.9)$ & $52(21.1)$ & \\
\hline Tertiary level & $426(88.9)$ & $53(11.1)$ & \\
\hline Employment status & & & 0.102 \\
\hline Unemployed & $220(82.7)$ & $46(17.3)$ & \\
\hline Employed & $400(87.1)$ & $59(12.9)$ & \\
\hline Parity & & & 0.275 \\
\hline Primiparous & $231(83.7)$ & $45(16.3)$ & \\
\hline Multiparous & $389(86.6)$ & $60(13.4)$ & \\
\hline Delivery method & & & $<0.001$ \\
\hline Vaginal delivery & $465(91.2)$ & $45(8.8)$ & \\
\hline Caesarean section & $155(72.1)$ & $60(27.9)$ & \\
\hline Complication after delivery & & & 0.164 \\
\hline No & $581(85.1)$ & $102(14.9)$ & \\
\hline Yes & $39(92.9)$ & $3(7.1)$ & - \\
\hline
\end{tabular}

Table 5 Multiple Logistic Regression of the associated factors of CAM use among postpartum women in Klinik Keramat, Malaysia $(n=725)$

\begin{tabular}{llll}
\hline Variables & Adjusted OR & $95 \%$ Cl (Lower, upper) & $P$ value \\
\hline Delivery Method, Vaginal delivery & 5.66 & 3.4549 .276 & $<0.001$ \\
$\quad$ Caesarean section & 1 & 1.13622 .082 & 0.033 \\
Religion, Muslim & 5.01 & 1.17616 .562 & \\
$\quad$ Non-Muslim & 1 & 1.5874 .133 \\
Ethnicity, Malay & 4.414 & & 0.028 \\
$\quad$ Non-Malay & 1 & 0.9322 .156 & \\
Education level, Tertiary level & 2.561 & 0.001 \\
$\quad$ Secondary level and below & 1 & 0.79611 .480 \\
Employment status, employed & 1.418 & & 0.103 \\
$\quad$ Unemployed & 1 & 0.9141 .007 & 0.104 \\
Complication after delivery, Yes & 3.023 & 1.0001 .000 \\
$\quad$ No & 1 & 0.959 & 0.163 \\
Age & 1 &
\end{tabular}


for acupressure and massage, followed by herbal medicine [14].

Our study showed that herbal medicine consumption among postpartum mothers was the second-most common modality of CAM usage. Surprisingly, among these mothers who consumed herbal medicine, more than half of them (57.1\%) reported neonatal jaundice in their newborn. The incidence rate was higher than that found in another local study conducted in a teaching hospital; a $49.1 \%$ rate of neonatal jaundice was reported among postpartum mothers who took herbal medicine after delivery [13].

In this study, we also determined that over half of the mothers had opted to use CAM therapies because they had seen positive results from other CAM users (52.1\%). This was followed by individuals who simply wanted 'to try out' those CAM therapies (27.6\%). We observed that the majority of our respondents had been influenced by their family members $(85.0 \%)$, reporting that they were their sole source of information regarding CAM, while only $1.1 \%$ received information regarding CAM from medical practitioners. Again, these findings were not surprising as prior studies on CAM use among postpartum women have also indicated that a majority of mothers in the postnatal period have used CAM on the recommendation of their family members, primarily their mothers or mothers-in-law, while very few of them had discussed this information with doctors $[11,13,15$, $23,27-30]$. The above results were also consistent with those from the literature, which suggested that CAM utilization had been constantly passed from one generation to another. The positive effects reported by one's ancestors, along with the respect given to tradition, has ensured that CAM is still widely utilized [30, 31].

Studies have stated that the utilization of CAM is predominantly based on a patient's perception, and the perceived natural features of CAM were responsible for their therapeutic effects [32]. This is similar to our result, in that most mothers in our sample population were satisfied with the use of CAM (80.3\%) and believed that it improved their overall physical health (61.8\%). Others have claimed that CAM reduces psychological stress post-delivery (15.2\%) and increases breast milk production $(13.7 \%)$. Only $6.9 \%$ of the participants observed weight loss while practising CAM.

Our study has demonstrated that Malay postpartum mothers have a higher likelihood of using CAM. The study, which was carried out in a tertiary hospital in Malaysia, has demonstrated similar findings, whereby Malay mothers ingest significantly more herbs in the postnatal period [13]. Chinese was reported to be less likely to consume CAM in another local study [15]. An explanation for this could be that herb ingestion is deeply rotten in traditional Malay beliefs [33].
Our study also showed that Muslim mothers had a higher probability of using CAM in the postnatal period in comparison to non-Muslims mothers. The significant association between Islamic beliefs and CAM use can perhaps be explained by the fact that the utilization of CAM has become a part of Islamic faith and that the cultural traditions have been greatly integrated into Islam [34, 35]. In addition, the fact that the population in this study were primarily Malay and Muslim may indirectly explain why being Muslim is one of the predictors of CAM use.

Similar to other previous studies, our study has reported that there is a higher tendency of postpartum mothers with tertiary education to utilize CAM $[10,11$, $15,22]$. This could be due to the fact that women with tertiary education have higher chances of being employed and consequently have higher earnings and can afford CAM. Furthermore, those with a higher education level may have a broader knowledge of CAM. This will further increase their self-empowerment in making their own health decisions [36].

It has been demonstrated in this study that postpartum women who had vaginal delivery use CAM more than those with other methods of delivery. These results are similar to those of a study conducted in Taiwan, which reported that those who had a vaginal delivery are more likely to use CAM compared to those who delivered via caesarean section [22]. Studies have shown that manipulative body-based practices are the most commonly practised method of CAM among postpartum mothers. This explains why those who delivered via caesarean section did not prefer to use CAM, because this therapy requires bodily movements that might be difficult and painful for mothers post caesarian section [10, $11,14,22,37]$.

Our study reported no association between age and CAM use among postpartum mothers, which is corroborated by other studies $[9,13,22]$. There are conflicting results for the relationship between CAM use among postpartum mothers and monthly household income $[10,27,28]$. However, our study found no significant relationship between monthly household income and CAM use in postpartum mothers [13].

In terms of obstetrical factors, this study has shown that complications after delivery and maternal parity are not associated with CAM use. To date, to the best of our knowledge, there has been no investigation into the association between CAM practice and the presence of postpartum complications. This study could serve as the first to explore the association between postpartum complications and CAM use. Additionally, our study has shown no association between maternal parity and CAM use. Although most studies previously have reported comparable findings [14, 22, 27], a local study done by 
Teoh et al. has shown that multiparous mothers have used significantly more CAM than primiparous mothers [13]. Further investigation would be required to better examine any associations between these factors and CAM usage.

\section{Strengths and limitations}

The sample size of this study is relatively larger than those in other existing literature. In addition, this study has not only identified socio-demographic factors affecting CAM use, but also explored the obstetrical factors that affect it, which has not been investigated by previous local studies, especially in the primary healthcare setting. Furthermore, we have also looked into additional data on experiences and perspectives towards CAM use in the postpartum period. One distinct finding in this study is the high incidence of neonatal jaundice (57.1\%) among mothers who took herbal medicines during the postpartum period. However, future research should be done to investigate the impact of CAM on this issue.

This study has some limitations. Firstly, time constraints were one of the most important factors that limited us from recruiting participants from other centres. Therefore, future studies should consider multiple centres. Secondly, since this is a cross-sectional study, data on every respondent were collected only once within the specified period. Therefore, we were unable to identify any temporal associations between the sociodemographic and obstetrical factors and CAM use. Therefore, only an association and no causal relation can be inferred from this study.

\section{Conclusion}

It was found that the prevalence of CAM use was high (8 out of 10) among postpartum mothers. Postpartum mothers who are Malay, Muslim, have a higher educational level and who have had spontaneous vaginal delivery tend to use CAM more. Manipulative body therapies, including massage, reflexology, hot stone compression and body wrapping, were the most widely used CAM modalities, followed by biological-based therapies. However, our study showed that more than half of the mothers who consumed herbal medicine reported neonatal jaundice in their newborn. Urgent intervention, such as education regarding the risks of herbal consumption and neonatal jaundice during the antenatal period is required.

\section{Abbreviation}

CAM: Complementary Alternative Medicine; SPSS: Statistical package for social sciences; WHO: World Health Organization; MREC: Medical Research Ethical Committee; MOH: Ministry of Health; USD: United States Dollar; RM: Ringgit Malaysia; OR: Odds Ratio; Cl: Confidence Interval; IQR: Interquartile Range

\section{Acknowledgements}

We would like to extend our gratitude to the Gombak district Health Office and Director of Health for their support of our study. The author would like to thank all the primary care doctors and staffs for providing support during the data collection. Last but not least, we would like to thank the Director General of Health Malaysia for his permission to publish this article.

\section{Authors' contributions}

SMC, NFNYF, CAT, DHAD and ZAZ were involved in the study design. Data collection was done by NFNYF. Data analysis and manuscript drafting were done by NFNYF and SMC. All authors had read and approved the final manuscript.

\section{Funding}

The study was supported by research grant from Universiti Putra Malaysia (GP-IPS/2018 9612500). The funder had no role in study design, data collection and analysis, decision to publish or preparation of the manuscript.

Availability of data and materials

The data is available and will be provided upon request to the corresponding author.

Ethics approval and consent to participate

Ethical approval was obtained from the Medical Research and Ethics Committee (MREC), Ministry of Health Malaysia (NMRR-16-2474-32261) and MREC JKEUPM, Universiti Putra Malaysia (UPM/TNCPI/RMC/1.4.18.2) before data collection. An informed written consent was obtained from respondents prior to the study. Publication approval was obtained from National Institutes of Health with the reference number of KKM.NIHSEC.8004/4/1 Jld 64(16)

Consent for publication

Not applicable

\section{Competing interests}

The authors declare that they have no competing interests.

\section{Author details}

${ }^{1}$ Klinik Kesihatan AU2 Keramat, Ministry of Health Malaysia, Taman Sri Keramat, Jalan AU2, Putrajaya 54200, Selangor, Malaysia. ${ }^{2}$ Department of Family Medicine, Faculty of Medicine and Health Sciences, Universiti Putra Malaysia, 43400 Serdang, Malaysia. ${ }^{3}$ Malaysian Research Institute on Ageing, Universiti Putra Malaysia, Serdang 43400, Malaysia. ${ }^{4}$ Department of

Biomedical Science Faculty of Medicine and Health Sciences, Universiti Putra Malaysia, Serdang 43400, Malaysia.

Received: 5 January 2019 Accepted: 8 June 2020

Published online: 26 June 2020

\section{References}

1. Qi Z. WHO traditional medicine strategy 2014-2023, vol. 76. Geneva: World Health Organization; 2013. https://www.who.int/medicines/publications/ traditional/trm_strategy14_23/en/ Accessed 24 Feb 2019.

2. Barnes PM, Bloom B, Nahin RL. Complementary and alternative medicine use among adults and children: United States 2007 American Psychological Association. Nat Health Stat Rep. 2008;10(12):1-23.

3. Ministry of Health. Traditional and Complementary Medicine Programme in Malaysia: Handbook. Kuala Lumpur: Traditional \& Complementary Medicine Division; 2011. p. 1-50.

4. Ching SM, Zakaria ZA, Paimin F, Jalalian M. Complementary alternative medicine use among patients with type 2 diabetes mellitus in the primary care setting: a cross-sectional study in Malaysia. BMC Complement Altern Med. 2013;13(1):148.

5. Ching SM, Vasudevan R, Zakaria ZA, Paimin F. Frequency of complementary and alternative medicine usage among Malaysian hypertensive subjects. Life Sci J. 2013;10:2526-31.

6. Vachirayonstien T, Promkhatkaew D, Bunjob M, Chueyprom A, Chavalittumrong P, Sawanpanyalert P. Molecular evaluation of extracellular activity of medicinal herb Clinacanthus nutans against herpes simplex virus type-2. Nat Prod Res. 2010;24(3):236-45. 
7. Ching S, Ramachandran V, Gew LT, Lim SMS, Sulaiman WAW, Foo YL, Hoo F. Complementary alternative medicine use among patients with dengue fever in the hospital setting: a cross-sectional study in Malaysia. BMC Complement Altern Med. 2016;16(1):37.

8. Alam A, Ferdosh S, Ghafoor K, Hakim A, Juraimi AS, Khatib A, Sarker ZI. Clinacanthus nutans: a review of the medicinal uses, pharmacology and phytochemistry. Asian Pac J Trop Med. 2016;9(4):402-9.

9. Ali-Shtayeh MS, Jamous RM. Plants used during pregnancy, childbirth, postpartum and infant healthcare in Palestine. Complement Ther Clin Pract. 2015;21(2):84-93.

10. Birdee GS, Kemper KJ, Rothman R, Gardiner P. Use of complementary and alternative medicine during pregnancy and the postpartum period: an analysis of the National Health Interview Survey. J Womens Health. 2014 23(10):824-9.

11. Johnson PJ, Kozhimannil KB, Jou J, Ghildayal N, Rockwood TH. Complementary and alternative medicine use among women of reproductive age in the United States. Womens Health Issues. 2016;26(1):40-7.

12. Ministry of Health: Health technology assessment section (mahtas),traditional postnatal care in restoring women's physical and mental health. chrome-extension://oemmndcbldboiebfnladdacbdfmadadm/https:// www.moh.gov.my/index.php/database_stores/attach_download/348/267. Available on 12th May 2020; 2015.

13. Teoh CS. Herbal ingestion during pregnancy and post-partum period is a cause for concern. Med J Malaysia. 2013;68(2):157-60

14. Zeng Y, Zhou Y, Chen P, Luo T, Huang M. Use of complementary and alternative medicine across the childbirth spectrum in China. Complement Ther Med. 2014;22(6):1047-52.

15. Ali RS, Gnanasan S, Farooqui M. Women's perspectives towards traditional and complementary medicine used to conceive, during pregnancy and the postpartum period. Complement Ther Clin Pract. 2018;30:109-15.

16. Mar SO, Amirah MS, Farahiyah SK, Sugathan S. Complementary medicine practices for pregnancy and postpartum health: a study among malaysian women who gave birth in a tertiary centre. Asian J Med Health Sci. 2019; 2(2):64-77.

17. Gossler SM. Use of complementary and alternative therapies during pregnancy, postpartum, and lactation. J Psychosoc Nurs Ment Health Serv. 2010;48(11):30-6.

18. Klinik Kesihatan AU2 Keramat: Laporan Bulanan-Tahunan Kedatangan Pesakit Luar KK AU2 Keramat Mengikut Umur-Jantina dan Kumpulan Etnik; 2018.

19. Stanley Lemeshow, David W Hosmer Jr, Janelle Klar, Lwanga SK: Adequacy of Sample Size in Health Studies ISBN 047192517 9: John Wiley \& Sons Ltd. Baffins Lane, Chichester West Sussex P019 1 UD, England; 1990.

20. Ministry of Health: REKOD KESIHATAN IBU Available from: http://fh.moh.gov. my/v3/index.php/component/jdownloads/send/18-sektor-kesihatanibu/222-rekod-kesihatan-ibu-kik1a96pind-2012-simpanan-ibu-2014?option= com_jdownloads. Accessed 14 Aug 2017.

21. Dennis C-L, Fung K, Grigoriadis S, Robinson GE, Romans S, Ross L. Traditional postpartum practices and rituals: a qualitative systematic review. Womens Health. 2007:3(4):487-502.

22. Chuang C-H, Chang P-J, Hsieh W-S, Tsai Y-J, Lin SJ, Chen PC. Chinese herbal medicine use in Taiwan during pregnancy and the postpartum period: A population-based cohort study. Int J Nurs Stud. 2009;46(6):787-95.

23. Sim TF, Sherriff J, Hattingh HL, Parsons R, Tee LB. The use of herbal medicines during breastfeeding: a population-based survey in Western Australia. BMC Complement Altern Med. 2013;13(317):1-10.

24. Withers M, Kharazmi N, Lim E. Traditional beliefs and practices in pregnancy, childbirth and postpartum: a review of the evidence from Asian countries. Midwifery. 2018;56:158-70.

25. Onyiapat J-LE, Okoronkwo IL, Ogbonnaya NP. Complementary and alternative medicine use among adults in Enugu, Nigeria. BMC Complement Altern Med. 2011;11:19.

26. Nguyen D, Gavaza P, Hollon L, Nicholas R. Examination of the use of complementary and alternative medicine in central Appalachia, USA. Rural Remote Health. 2014;14:2484.

27. Tang L, Lee AH, Binns CW, Hui YV, Yau KKW. Consumption of Chinese herbal medicines during pregnancy and postpartum: a prospective cohort study in China. Midwifery. 2016;34:205-10.

28. Hori S, Mihaylov I, Vasconcelos JC, McCoubrie M. Patterns of complementary and alternative medicine use amongst outpatients in Tokyo Japan. BMC Complement Altern Med. 2017;8(1):14
29. Thomson P, Jones J, Evans JM, Leslie SL. Factors influencing the use of complementary and alternative medicine and whether patients inform their primary care physician. Complement Ther Med. 2012;20(1-2):45-53.

30. Abdul Ghani Radiah, Salehudin Saezah: Traditional Belief and Practice on Postpartum Recovery among Mothers in East Coast of Peninsular Malaysia. MATEC Web of Conferences 2018, 150(MATEC Web Conf. Volume 150, 2018 Malaysia Technical Universities Conference on Engineering and Technology (MUCET 2017) Article Number 05067):1-10.

31. World Health Organization. Legal status of traditional medicine and complementary/alternative medicine: a worldwide review: World Health Organization; 2001. Available from: https://books.google.com.my/books?id= rPOyQAAACAAJ.

32. Bahall M, Edwards M. Perceptions of complementary and alternative medicine among cardiac patients in South Trinidad: a qualitative study. BMC Complement Altern Med. 2015:15:99.

33. Jamaludin SS. Beliefs and practises surrounding postpartum period among malay women. Kota Kinabalu: School of Social Sciences, Universiti Sains Malaysia; 2014. p. 409-17. Available on https:/pdfs.semanticscholar.org/f3d7/ cad194b6226663602d57f511771fe73168fb.pdf. http://WorldConferences.net.

34. Hutch RA. Health and healing: spiritual, pharmaceutical, and mechanical medicine. J Religion Health. 2013;52(3):955-65.

35. Micozzi MS. Fundamentals of complementary and alternative medicine (fundamentals of complementary and integrative medicine). 5th ed. Elsevier; 2015. https://www.elsevier.com/books/fundamentals-of-complementaryand-alternative-medicine/micozzi/978-1-4557-7407-4.

36. Osamor PE, Grady C. Women's autonomy in health care decision-making in developing countries: a synthesis of the literature. Int J Womens Health. 2016;8:191-202.

37. Kealy MA, Small RE, Liamputtong P. Recovery after caesarean birth: a qualitative study of women's accounts in Victoria, Australia. BMC Pregnancy Childbirth. 2010:10:47.

\section{Publisher's Note}

Springer Nature remains neutral with regard to jurisdictional claims in published maps and institutional affiliations.
Ready to submit your research? Choose BMC and benefit from:

- fast, convenient online submission

- thorough peer review by experienced researchers in your field

- rapid publication on acceptance

- support for research data, including large and complex data types

- gold Open Access which fosters wider collaboration and increased citations

- maximum visibility for your research: over $100 \mathrm{M}$ website views per year

At $\mathrm{BMC}$, research is always in progress.

Learn more biomedcentral.com/submission 